\title{
Tesis doctorals 2018
}

Doctorand/a: Jacques Aviñó, Constanza

Títol: Discursos y prácticas sexuales de usuarios de saunas gay. Una aproximación desde las masculinidades

Any: 15/11/2018 | Universitat: URV

Direcció: Romaní Alfonso, Oriol; Caylà Buquera, Joan Artur

Doctorand/a: Cirera Serrallonga, Eva

Títol: El jardí de les delícies. Interacció humana en un espai de neurorehabilitació

Any: 30/10/2018 | Universitat: URV

Direcció: Comelles Esteban, Josep M.

Doctorand/a: Serrano Miguel, Mercedes Concepción

Títol: Del exilio a la ciudadania. Experiencias dialógicas en el marco de la salud mental colectiva

Any: 10/07/2018 | Universitat: URV

Direcció: Martínez Hernáez, Àngel

Doctorand/a: Ventura Garcia, Laia

Títol: Mal de Chagas: una etnografia corporeïtzada sobre el risc latent Any: 20/06/2018 | Universitat: URV

Direcció: Martínez Hernáez, Àngel

TDX: http://hdl.handle.net/10803/663294 